\title{
İndoksakarb Kalıntısı ve Bozunma Ürünü için Yeni Bir Tayin Yöntemi Geliştirilmesi
}

\author{
Development of a New Determination Method for Indoxacarb Residue and Its \\ Degradation Product
}

\author{
Soner ÇUBUK ${ }^{(D)}$, Adnan AYDIN 11,2 \\ ${ }^{1}$ Marmara Üniversitesi Fen-Edebiyat Fakültesi Kimya Bölümü, 34722, Kadıköy-İstanbul. \\ 2 İstanbul Bilim Üniversitesi, Sağllk Bilimleri Fakültesi, Beslenme ve Diyetetik Bölümü, 34394, Şişli- İstanbul.
}

Öz

Günümüzde özellikle son 20 yıl süresince kullanımı çarpıcı bir şekilde artan pestisitler, modern tarımda böcekler, yabani otlar, mikroorganizmalar gibi zararlıları kontrol altına almak ve ürün verimini arttırmak için kullanılmakta olup hedef olmayan su, toprak ve gıdaları kirletmelerinin yanı sıra insan, evcil hayvanlar, bal arıları ve kuşlar için potansiyel sağlık riski gösterebilmektedirler. Zehirli olmalarının yanı sıra aynı zamanda bu bileşikler kanser yapıcı oluşumlara da sebep olurlar. Böceklerin ve yabani otların bu kimyasallara olan dayanıklılı̆̆ının artması sonucu dünya çapında pestisit kalıntı problemlerine yol açan daha fazla pestisit geliştirilmiş ve daha yüksek dozlarda kullanılmaya başlanmıştır. Bununla birlikte pestisitler, besin zincirine çeşitli yollarla girerek canlıların vücutlarında biyolojik birikime uğramakta ve bu besin zincirinde ilerlerken her aşamada daha büyük miktarlara erişmektedirler.

Balın da arasında bulunduğu gıdalar başta olmak üzere birçok matristeki pestisitlerin analizinin yapılması canlıların ona ne oranda maruz kaldığının doğru bir şekilde değerlendirilmesi bakımından büyük bir önem arz etmektedir. Bu nedenle pestisitlere ait kalıntı seviyelerinin tespiti ve kullanılan metotların güncel mevzuatlarda yer alan tolere edilebilir kalıntı konsantrasyonları da kapsaması beklenmektedir. Son yıllarda bu alanda bazı çalışmalar yapılmış olmasına rağmen ülkemizde ballardaki pestisit tayinleriyle ilgili çok az çalışma bulunmaktadır.

Çalışmamızda bal örneklerinde İndoksakarb ((S)-7-kloro-3-[meteksikarbonil-(4-trifluorometoksi-fenil)-karbamoil]-2,5-dihidro-indeno[1,2-e][1,3,4] oksadiazin-4a(3H)-karboksilik asit metil esteri) kalıntısının ve bozunma ürününün belirlenmesi için yeni bir yöntem geliştirilmiştir. Diklorometan ile ekstraksiyon sonrasında, Gaz Kromatograf-Kütle Spektrometresi kullanılarak indoksakarb ve bozunma ürü-

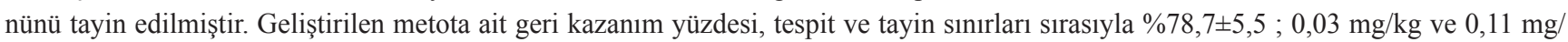
$\mathrm{kg}$ olarak hesaplanmıştır.

İndoksakarb ile kirletilmiş kestane, çiçek, çam ve ayçiçek balı numuneleri 3 farklı sıcaklıkta 8 ay süresince izlenmiş ve beşinci ayda 4-(trifluorometoksi)fenil izosiyanat, literatürde belirtilenlerden farklı bir bozunma ürünü olarak tespit edilmiștir.

Anahtar kelimeler: İndoksakarb, Bal, Bozunma Ürünü, GC-MS.

\begin{abstract}
Today pesticides, which have increased dramatically over the last 20 years, modern agriculture is used to control pests such as insects, weeds, microorganisms and to increase crop yields, but they pollute non-target water, soil and food, and can also present potential health risks for humans, domestic animals, honey bees and birds. Besides being toxic, they are also cause of cancerous formations. As a result of increasing resistance of insects and weeds to these chemicals, more pesticides have been developed worldwide and have begun to be applied to higher doses. In addition, pesticides enter the food chain in a various way, bioaccumulating in the bodies of living beings and reaching large quantities at each stage as they travel through this food chain. The analysis of pesticides in most of the matrices, especially the foodstuffs, including honey, including honey, is of great importance in terms of correctly assessing how the living beings are exposed to it. For this reason, it is expected that the residue levels of pesticides and the methods used will also include tolerable residue concentrations in current legislation. Although there have been some studies in this area in recent years, there are very few studies on pesticide determination in our country.In our study, a new method was developed to determine the residues of Indoxacarb ((S)-7-chloro-3-[methoxycarbon-
\end{abstract}


yl-(4-trifluoromethoxy-phenyl)- carbamoyl]-2,5-dihydro-indeno[1,2-e] $[1,3,4]$ oxadiazine- $4 \mathrm{a}(3 \mathrm{H})$ - carboxylic acid methyl ester) and its degradation product in honey samples. After extraction with dichloromethane, Indoxacarb and its degradation product were determined using Gas Chromatograph-Mass Spectrometry. The percent recovery, detection and detection limits of the developed method were $78.7 \pm 5.5 \% ; 0.03 \mathrm{mg} / \mathrm{kg}$ and $0.11 \mathrm{mg} / \mathrm{kg}$, respectively.

Samples of chestnut, flower, pine and sunflower honey spiked with indoxacarb were observed at 3 different temperatures for 8 months, and in the fifth month 4- (trifluoromethoxy) phenyl isocyanate was identified as a degradation product different from the ones mentioned in the literature.

Keywords: Indoxacarb, Honey, Degradation Product, GC-MS.

\section{GíRiş}

Pestisitler sayısız faydalarına rağmen doğamızı kirleten çok zehirli maddeler olup, canlıların vücutlarında biyolojik olarak birikmek suretiyle yoğunlaşmakta ve aynı zamanda gittikçe biyoderişiklenerek de daha büyük bir orana erişmektedir. Pestisitlerin bitki hastalıklarının ve böceklerin önlenmesi ve dolayısıyla ürün veriminin arttırılması amaçlarıyla kullanılması, her ne kadar tarımsal açıdan birtakım faydalar getirse de aşırı kullanımı çok fazla kalıntı bırakmakla kalmayıp aynı zamanda çevreyi de ciddi anlamda kirletmekte ve çeşitli yollarla besin zincirine katılarak insan ve hayvanların sağlığını ve hayatını tehdit etmektedir. Çoğunlukla pamuk, lahana, tatlı misır, patlıcan, domates gibi sebzeler, elma, armut ve kiraz dahil meyveler için kullanılmakta olan indoksakarb; organofosfatlar, karbamatlar ve pretreoidlere karşı direnç kazanmış böcekler için ilk ticari pirazolin tip insektisit olmakla birlikte, bu pestisitin çevre için güvenli, hedefte olmayan organizmalar için düşük zehirlilik, yüksek böcek öldürücü aktivite gibi özellikleri olduğu iddia edilmektedir. İnsanlar için her ne kadar pestisit veritabanlarında toksik etkilerine ait herhangi bir bilgi bulunmamasına rağmen, laboratuvarda hayvanlar üzerinde yapılan çalışmalar indoksakarba çeşitli yollarla maruz kalan sıçan, fare, tavşan ve köpeklerin olumsuz olarak etkilendiğini göstermektedir. Bu yan etkiler arasında burun akıntısı, gözlerde iltihaplı akıntı, hareketsizlik, uyku hali, titreme, spazmlar, salya ve hızlı kilo kaybı bulunmaktadır. Ayrıca indoksakarba maruz kalan sıçanların 20 gün içinde öldüğü de raporlanmıştır. Indoksakarbın hayvanlar üzerindeki bu olumsuz etkilerinin yanı sıra insanlar için de methemoglobinemi, hemolitik anemi, rabdomiyoliz adı verilen kas dokularının hasarı, akut solunum sıkıntısı sendromu, periferik nöropati olarak bilinen sinir ucu iltihabı, akut böbrek yetmezliği, ritim bozukluğu, kalp yetmezliği ve kalp durması gibi olumsuz durumları içeren nörolojik, kardiyovasküler ve hematolojik birçok vaka bildirilmiştir [1-3].

Balın insan tüketimi için güvenli olabilmesi herhangi bir kimyasal veya biyolojik kontaminasyondan arındırılmış olmasına bağlıdır. Pestisitler balın toplanması sırasında kovandaki hastalıkların tedavisinde kullanılmasıyla direkt olarak; toprak, hava, su aracılığı ile veya arıların bal yapmak için çiçeklerden nektar toplaması sırasında vücutlarına bulaşması ve kovana taşınması ile de indirekt olarak kirliliğe sebep olabilmektedir [4].

Günümüzde gıdalarda bulunan pestisit kalıntılarının miktarı kalite güvenliğinin önemli bir göstergesi haline gelmiş olup pestisit kalıntılarının etkin bir şekilde kontrol edilebilmesi için hızlı bir tespit yöntemi geliştirilmeye çalışılmaktadır. Kullanılan numune hazırlama yöntemleri genellikle, ekstraksiyon, izolasyon ve gerektiğinde analiz yapılacak matristen hedef pestisitin fraksiyonlanması için ek analitik adımlar içermektedir. Bu amaçla farklı ekstraksiyon teknikleri geliştirilmiştir. Pestisit kalıntısının belirlenmesi için örnek ön işleme teknikleri, esas olarak geleneksel sıv1-sıv1 ekstraksiyonu (LLE), matris katı faz dispersiyonu (MSPD), katı faz mikro ekstraksiyonu (SPME), katı faz ekstraksiyonu (SPE), jel kromatografi (GPC) ve QuEChERS (Hılı, Kolay, Ucuz, Etkili, Sağlam, Güvenli) yöntemlerini içermektedir. Geleneksel yöntemlerin zaman alıcı olma, çok fazla numuneye ihtiyaç duyma, daha az doğruluk, laboratuvar personeli için düşük güvenlik, otomasyona uygun olmama ve sızıntı problemleri gibi birçok dezavantajı bulunmaktadır. Literatürde baldaki pestisit kalıntı analizi için çeşitli metotlar önerilmiştir [5-7]. Öncelikle matristen analitin ekstrakte edilmesi gerekmektedir. Bunun için hekzan/asetonitril veya çözücü karışımları ile sıvı-sıvı ekstraksiyonu yapılabildiği gibi ODS-3 veya Florasil-5 kartuş kullanılarak katı faz ekstraksiyonu, süper kritik akışkan ekstraksiyonu veya katı faz mikro ekstraksiyonu da yap1labilmektedir [8-11]. Ekstraktlar genellikle Gaz Kromatograf- Kütle Spektrometresi (GC- MS), Gaz Kromatograf- Elektron Yakalama Dedektörü (GC-ECD), Gaz Kromatograf- Azot-Fosfor Dedektörü (GC- NPD), Gaz Kromatograf- Alev İyonizasyon Dedektörü (GC-FID), kapiler GC-MS, Gaz Kromatograf-Atomik Emisyon Dedektörü (GC-AED), Sıvı Kromatografi- Kütle Spektrometresi (LC-MS), Yüksek Basınçlı Sıvı Kromatografi- Diyot Dizinli Dedektör (HPLC-DAD) ve Yüksek Basınçlı Sıvı Kromatografisi (HPLC) kullanılarak analiz edilmektedir [9-10,12-17].

Çalışmamız iki aşamadan oluşmaktadır. İlk aşama bal ortamındaki indoksakarbın tayin edilebilmesi için yeni bir yöntem geliştirilmesini içermekte olup tayin için gerekli uygun şartlar belirlenmiştir. Bu amaçla indoksakarb ile 
kirletilmiş bal örneklerinden ekstraksiyon için en uygun çözücünün belirlenmesi yapılmış, ardından tayin için en uygun GC-MS şartlarına karar verilmiştir. İkinci aşamada ise çiçek, kestane, çam ve ayçiçeği bal numuneleri indoksarbın bilinen bir konsantrasyonu ile kirletilmiş ve oda sıcaklığı, $30^{\circ} \mathrm{C}$ ve $40^{\circ} \mathrm{C}$ 'de 8 ay süresince izlenerek bu süre zarfinda indoksakarb ve bozunma ürünün belirlenmesi yapılmıştır. Yapılan analizler sonucunda indoksakarbın literatürde daha önce karşılaşılmamış olan 4-(triflorometoksi)fenil izosiyanat adlı bir bozunma ürünü ile karşılaşılmıştır. Geliştirilen yöntem ile bal numunelerinde indoksakarb kalıntısı güncel mevzuatların kriterlerini de karşılayacak şekilde [18], kolay, hızlı ve hassas olarak yapilabilmektedir.

\section{MATERYAL VE YÖNTEM}

\section{I. Kimyasal Maddeler}

Çalışmalarımızda kullanılan kimyasal maddelerin tamamı GC saflıkta olup indoksakarb Sigma'dan, diklorometan, etil asetat, kloroform, asetonitril, aseton ve metanol Merck’ten temin edilmiştir.

\subsection{Deneysel Yöntemler}

Çalışmamızda öncelikle bal numunelerindeki indoksakarbın tayini için yöntem geliştirilmesi amacıyla bu pestisit ile kirletilmiş bal örneklerinden ekstraksiyonunda kullanılacak en uygun çözücüye ve tayin için en uygun GC-MS şartlarına karar verilmiştir. İkinci aşamada ise çiçek, kestane, çam ve ayçiçeği balı numuneleri indoksarbın bilinen bir konsantrasyonu ile kirletilmiş ve oda sıcaklığ, $30^{\circ} \mathrm{C}$ ve $40^{\circ} \mathrm{C}$ 'de 8 ay süresince izlenerek bu süre zarfinda indoksakarb ve bozunma ürünün belirlenmesi yapılmıştır.

Uygun GC-MS şartlarının belirlenmesi için asetonitril içinde hazırlanmış indoksakarb çözeltisi kullanılarak yapılan çalışmada kromatogramdaki piklerin simetrik olması, kuyruklanma yapmamış olması gibi kromatografik olarak kabul edilebilir pik karakteristiklerine ulaşılması esas alınmış ve farklı sıcaklık programları, farklı enjeksiyon hacimleri gibi değişkenler incelenmiştir. GC-MS şartların belirlendikten sonra kalibrasyon grafiği hazırlanması aşamasına geçilmiştir. Asetonitrilde çözülerek hazırlanmış olan İndoksakarb çözeltisinden (100 ppm) uygun hacimler alınarak s1rasıyla 9 farklı konsantrasyonda olacak şekilde standart çözeltiler hazırlanmıştır. Karar verilen GC-MS şartlarında elde edilen grafik Şekil 1'de verilmiştir.

Ekstraksiyon için uygun çözücü seçimi yapılması amacryla ise $1 \mathrm{ppm}$ düzeyinde indoksakarb ile kirletilmiş bal örnekleri için farklı çözücülerle sıvı-sıvı ekstraksiyonu çalışmaları yapılmıştır. Elde edilen ekstraktlar azot gazı altında buharlaştırılmış ve daha önce karar verilen şartlarda GC-MS ile analiz edilmiştir. Bu şartlar altında elde edilen kromatogram ve spektrum Şekil 2'de, geri kazanım yüzdelerini gösteren değerler Tablo 1'de verilmiştir.

Tespit ve tayin sınırlarının hesaplanması için $0,1 \mathrm{mg} / \mathrm{kg}$ konsantrasyonunda indoksakarb içeren 6 farklı bal örneği ile çalışılmıştır. Baldan indoksakarb ekstraksiyonu için yapılan işlemler aynı şekilde bu bal örneklerine de uygulanmıştır. Sonuçlara ait ortalama değer ile standart sapma değerinin 3 katıyla toplanmasıyla tespit sinırı (LOD), standart sapma değerinin 6 katıyla toplanmasıyla tayin sınırı (LOQ) elde edilmiştir.

İndoksakarb kalıntısının ve bozunma ürününün belirlenmesi amacıyla İstanbul Arı Yetiştiricileri Birliği’nden temin edilen çam, ayçiçeği ve kestane balları ile marketten temin edilen çiçek balı kullanılarak yapılan çalışmada, 8 ay süresince oda sicaklığ $, 30^{\circ} \mathrm{C}, 40^{\circ} \mathrm{C}$ olmak üzere 3 farklı sicaklıkta bekletilmek üzere 100 'er gram bal örnekleri alınmış ve üzerine aseton içinde hazırlanmış 2000 ppm'lik indoksakarb çözeltisinden 1'er mL katıldıktan sonra mekanik olarak uygun bir hızda karıştırılan bal örneklerinde son indoksakarb konsantrasyonun $20 \mathrm{mg} / \mathrm{kg}$ olması sağlanmıştır. Bu ballardan belirli zamanlarda yaklaşık 1'er gramlık tartımlar alınarak $1 \mathrm{~mL}$ saf su ile girdaplı karıştırıcı yardımıyla homojenizasyon işlemi yapılmıştır. Bunu takiben 2 defa 2 'şer $\mathrm{mL}$ diklorometan ile dakikada 2000 devir hızıyla dönen santrifüj cihazında santrifüjlenmiş ve ele geçen organik fazlar birleştirilmiştir. Organik faz azot gazı altında uzaklaştırıldıktan sonra elde edilen kalıntı $1 \mathrm{~mL}$ asetonitril ile çözülerek GC-MS cihazında karar verilen şartlarda analiz yapılmıştır. Benzer şekilde indoksakarb içermeyen bal örneği şahit olarak kullanılmış ve her sıcaklık değeri için aynı şekilde ekstraksiyon işlemine tabi tutulmuştur. Yapılan çalışmalar sonucunda indoksakarb miktarındaki değişimleri gösteren grafikler; çiçek balı için Şekil 3'te, kestane balı için Şekil 4 'te, çam balı için Şekil 5'te, ayçiçek balı için Şekil 6'da verilmiş̧ir.

\section{BULGULAR VE TARTIŞMA}

Geliştirilen yönteme ait en uygun şartların belirlenmesi amacıyla farklı enjeksiyon hacmi ve farklı sıcaklık programlarında yapılan çalışmalar sonucunda kromatografik olarak kabul edilebilir pik karakteristiklerine ulaşılması esas alınarak yapılan değerlendirmeler ışığında tespit edilen analiz koşulları aşağıda maddeler halinde verilmiştir:

- Kolon: HP-5-MS (uzunluk: $30 \mathrm{~m}$, iç çap: 0,25 mm, film kalınlığ1: $0,25 \mu \mathrm{m})$ 
- Hareketli faz: Dakikada $1 \mathrm{~mL}$ akış hızında Helyum gazı

- $\quad$ Enjeksiyon sicaklığı: $300{ }^{\circ} \mathrm{C}$

- Kolon başlangıç sıcaklığı: $70{ }^{\circ} \mathrm{C}$

- Kolon son sicaklığ $1: 300{ }^{\circ} \mathrm{C}$

- İyonizasyon enerjisi: $70 \mathrm{eV}$

- Enjeksiyon türü: Ayrımsız (Splitless)

- Enjeksiyon hacmi: $2 \mu \mathrm{L}$

Kalibrasyon grafiğinin oluşturulması için 0,$1 ; 0,3 ; 0,5 ; 1,0$; 3,$0 ; 5,0 ; 10,0 ; 15,0 ; 20,0$ ppm konsantrasyonlarında asetonitril içerisinde hazırlanmış olan indoksakarb standart çözeltileri kullanılmış olup ilgili grafik Şekil 1'de yer almaktadır. Yapılan çalışmalar sonucunda yönteme ait tespit ve tayin sınırları sırasıyla $0,03 \mathrm{mg} / \mathrm{kg}$ ve $0,11 \mathrm{mg} / \mathrm{kg}$ olarak hesaplanmıştır.

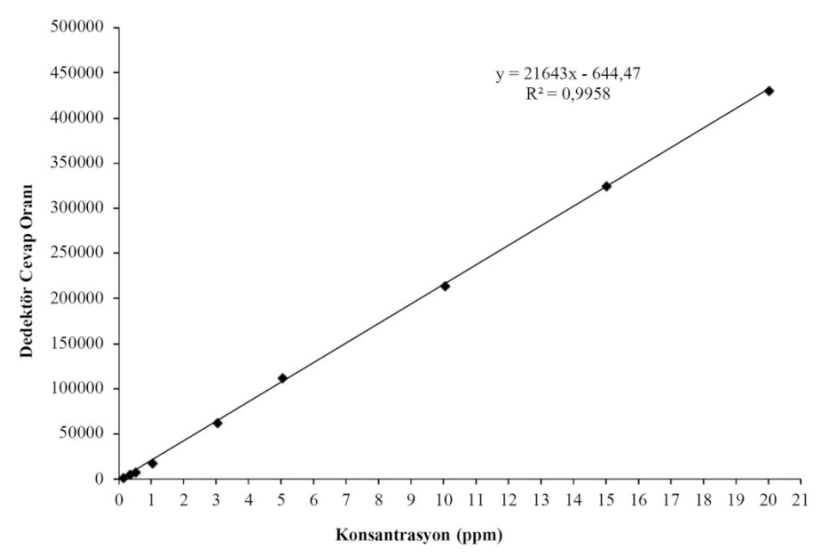

Şekil I. İndoksakarba ait Kalibrasyon Grafiği.
Yönteme ait karar verilen analiz şartları kullanılarak bal numunelerinden indoksakarbın ekstraksiyonu için en uygun çözücünün tespiti amacıyla yapılan çalışmalar sonucunda elde edilen geri kazanım değerleri ve kromatogramlar incelendiğinde, geri kazanımı oranı olarak yeterli bir değer sağlayan ve karmaşı1k olmayan bir kromatogram veren diklorometana en uygun çözücü olarak karar verilmiştir. Tablo 1 'den de görülebileceği gibi en yüksek geri kazanım oranını veren çözücü $(\% 78,7 \pm 5,5)$ diklorometan olmuştur. Çalışmanın ilerleyen aşamalarındaki bal ortamından indoksakarbın ekstraksiyonunda diklorometan kullanılmıştır.

Tablo I. Geri Kazanım Yüzdeleri (\%95 Güven Aralı̆̆ı, n=6)

\begin{tabular}{ll}
\hline Çözücü & $\%$ Geri Kazanım \\
\hline Etil Asetat: Kloroform $(80: 20)(\mathrm{h} / \mathrm{h})$ & $56,7 \pm 9,2$ \\
Kloroform & $67,2 \pm 9,4$ \\
Asetonitril & - \\
Diklorometan & $78,7 \pm 5,5$ \\
\hline
\end{tabular}

İstanbul Arı Yetiştiricileri Birliği'nden ve marketten temin edilen bal örnekleri, oda sicaklığ1, $30{ }^{\circ} \mathrm{C}$ ve $40{ }^{\circ} \mathrm{C}$ ' de bekletilmek suretiyle 8 ay boyunca indoksakarb miktarındaki değişimler izlenmiştir.

İlgili grafikler incelendiğinde çiçek balı örneğinde bulunan indoksakarb miktarları oda sıcaklığında $18,5 \mathrm{mg} / \mathrm{kg}$ değerinden 7,2 mg/kg değerine; $30^{\circ} \mathrm{C}$ 'de $17,6 \mathrm{mg} / \mathrm{kg}$ değerinden $7,4 \mathrm{mg} / \mathrm{kg}$ değerine ve $40^{\circ} \mathrm{C}$ ' de $19,9 \mathrm{mg} / \mathrm{kg}$ değerinden $7,7 \mathrm{mg} / \mathrm{kg}$ değerine düşmektedir (Şekil 3).

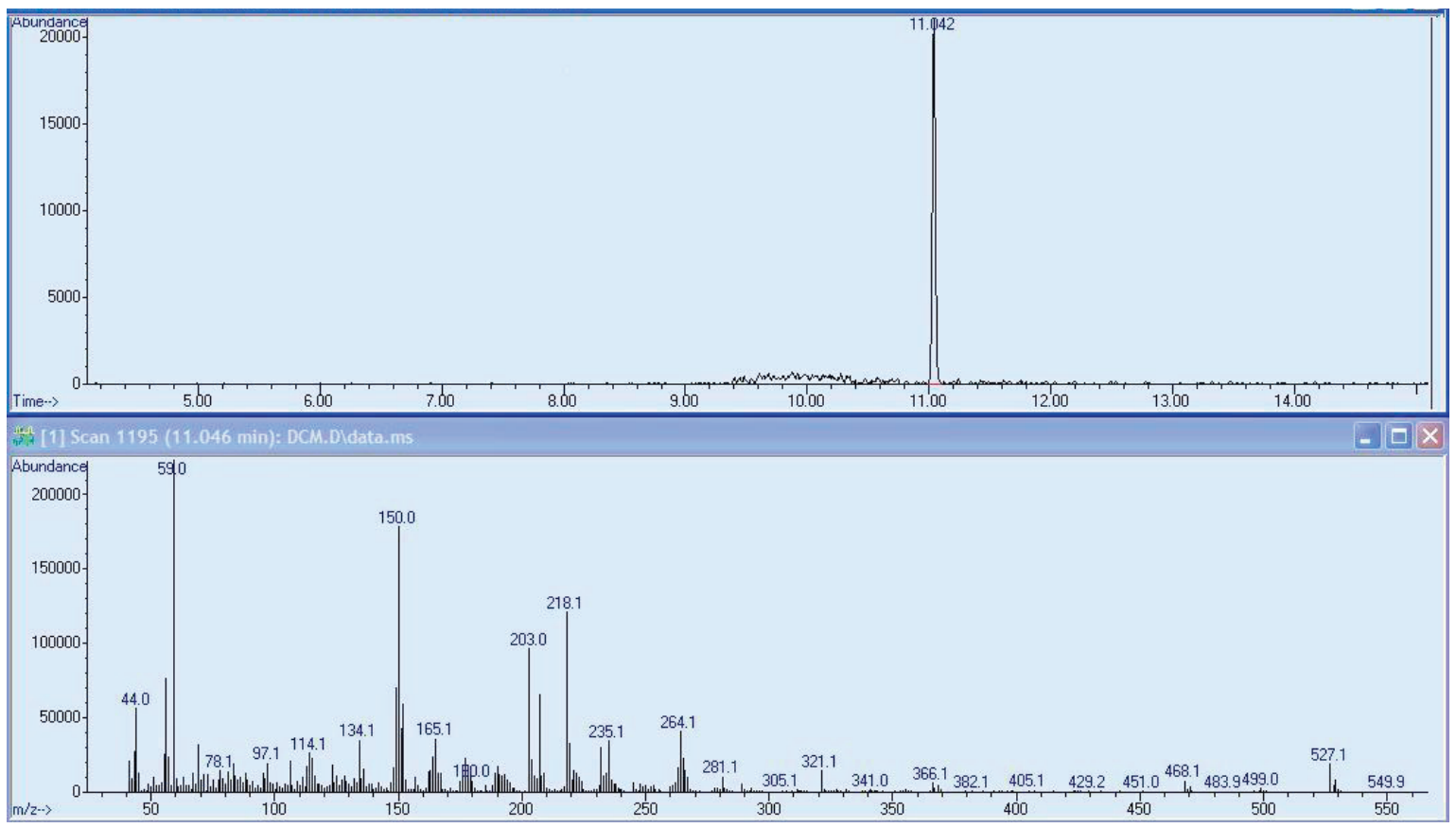

Şekil 2. Diklorometan İle Yapılan Ekstraksiyon Sonucu Elde Edilen Kromatogram ve Spektrum. 
Kestane balı örneğine ait sonuçlara bakıldığında; oda sicaklığ $1,30{ }^{\circ} \mathrm{C}$ ve $40{ }^{\circ} \mathrm{C}$ sicakliklarında indoksakarb miktarlarının sırasıyla $18,6 \mathrm{mg} / \mathrm{kg}$ değerinden $7,0 \mathrm{mg} / \mathrm{kg}$ değerine; $19,4 \mathrm{mg} / \mathrm{kg}$ değerinden $6,9 \mathrm{mg} / \mathrm{kg}$ değerine; $18,5 \mathrm{mg} /$ $\mathrm{kg}$ değerinden $7,9 \mathrm{mg} / \mathrm{kg}$ değerine değiştiği görülmüştür (Şekil 4).

Çam balı örneğinde ise indoksakarb miktarlarının oda s1caklığında $18,2 \mathrm{mg} / \mathrm{kg}$ değerinden $7,2 \mathrm{mg} / \mathrm{kg}$ değerine; 30 ${ }^{\circ} \mathrm{C}^{\prime}$ de $21,6 \mathrm{mg} / \mathrm{kg}$ değerinden $7,8 \mathrm{mg} / \mathrm{kg}$ değerine ve 40 ${ }^{\circ} \mathrm{C}$ 'de $20,8 \mathrm{mg} / \mathrm{kg}$ değerinden $6,8 \mathrm{mg} / \mathrm{kg}$ değeri olacak şekilde azaldığı tespit edilmiştir (Şekil 5).

Yine benzer şekilde 8 . ay sonunda ayçiçeği balı örneğindeki indoksakarb miktarları oda sıcaklığ $1,30^{\circ} \mathrm{C}$ ve $40^{\circ} \mathrm{C}$ sıcaklıklarında sırasıyla $18,7 \mathrm{mg} / \mathrm{kg}$ değerinden $7,2 \mathrm{mg} / \mathrm{kg}$ değerine; $20,9 \mathrm{mg} / \mathrm{kg}$ değerinden $6,9 \mathrm{mg} / \mathrm{kg}$ değerine; 19,1 $\mathrm{mg} / \mathrm{kg}$ değerinden $6,8 \mathrm{mg} / \mathrm{kg}$ değerine azalmaktadır (Şekil 6).

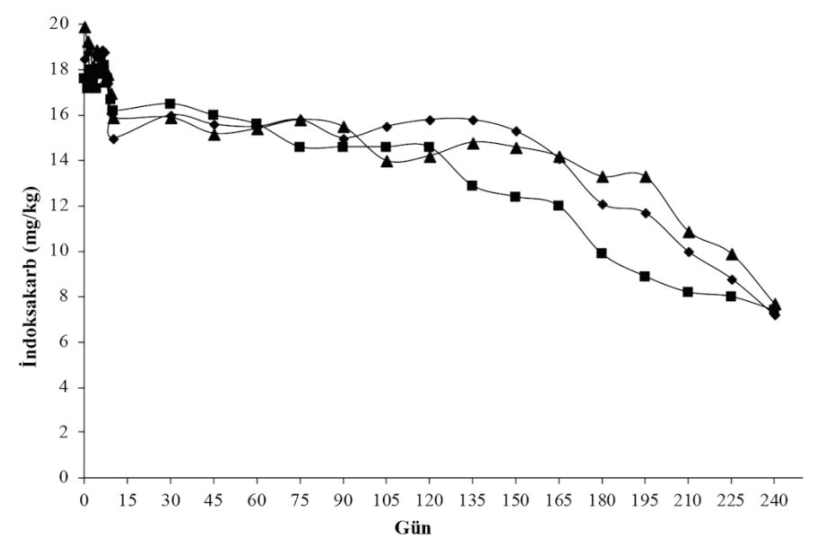

Şekil 3. Oda Sicaklığ $\breve{1}_{\text {u }), 30}{ }^{\circ} \mathrm{C}$ (n)ve $40{ }^{\circ} \mathrm{C}$ (p)'de Bekletilen Çiçek Balına Ait İndoksakarb Değişimi.

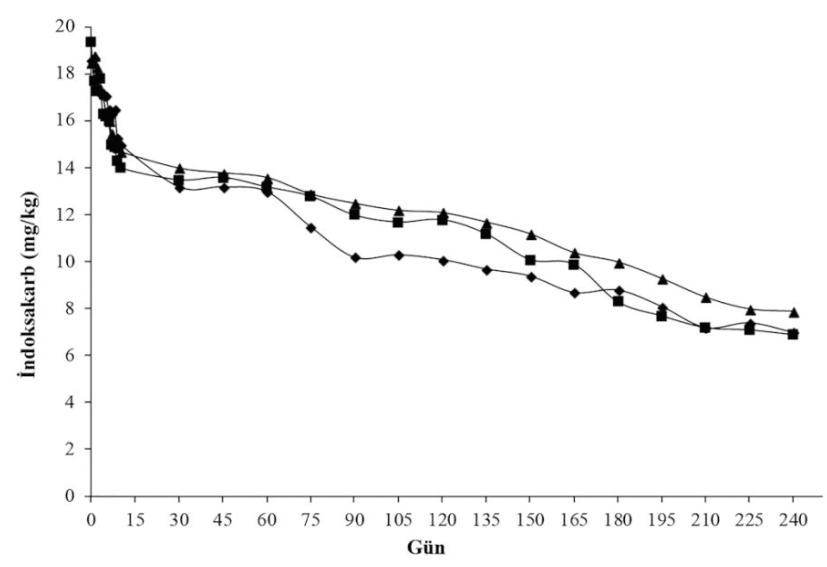

Şekil 4. Oda Sicaklığ 1 (u), $30{ }^{\circ} \mathrm{C}$ (n)ve $40{ }^{\circ} \mathrm{C}$ (p)'de Bekletilen Kestane Balına Ait İndoksakarb Değişimi.

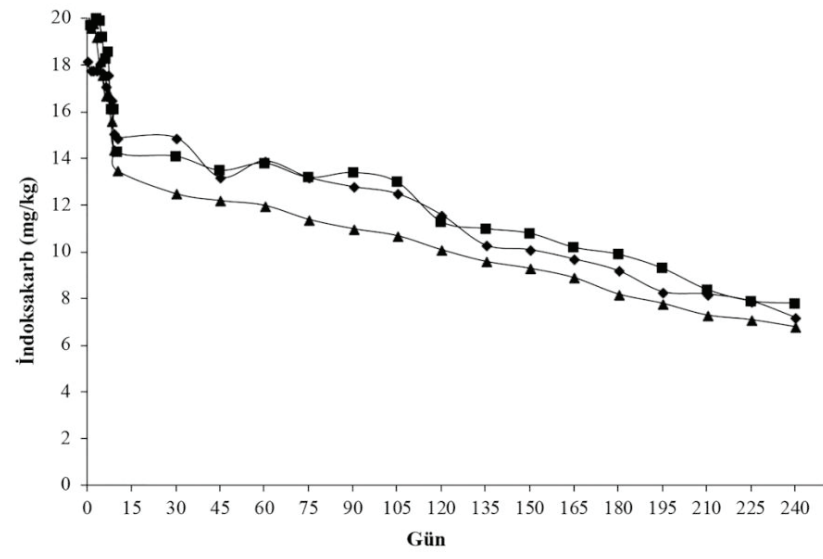

Şekil 5. Oda Sicaklığ 1 (u), $30{ }^{\circ} \mathrm{C}$ (n)ve $40{ }^{\circ} \mathrm{C}$ (p)'de Bekletilen Çam Balına Ait İndoksakarb Değişimi.

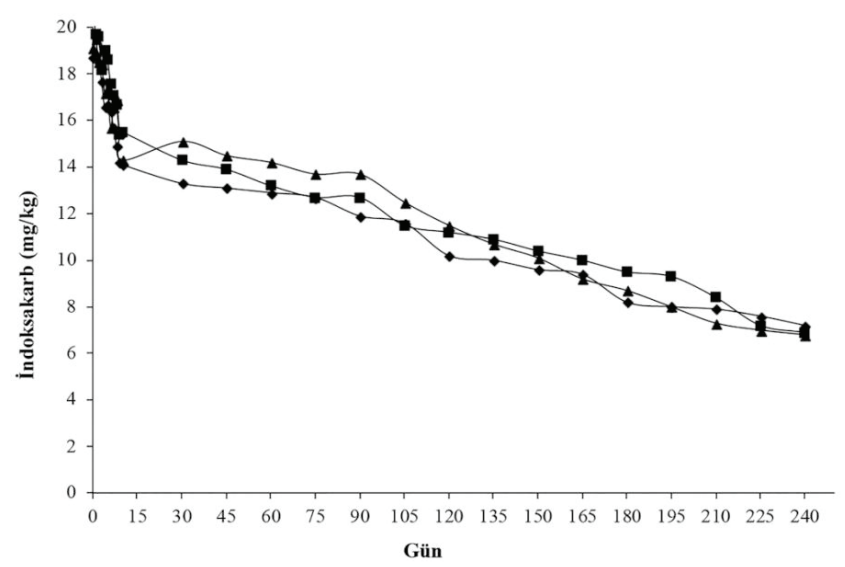

Şekil 6. Oda Sicaklığ (u), $30{ }^{\circ} \mathrm{C}$ (n)ve $40{ }^{\circ} \mathrm{C}$ (p)'de Bekletilen Ayçiçeği Balına Ait İndoksakarb Değişimi.

\section{I. Bozunma Ürünü İçin GC- MS Sonucu}

Agilent firmasının kullandığı yazılım programında mevcut Pestisit; NIST ve Wiley kütüphanelerinde yapılan tarama sonucunda ilgili bozunma ürünü için 4-(triflorometoksi)fenil izosiyanat adlı madde bulunmuştur. İlgili kromatogram ve spektrumlar Şekil 7 ve Şekil 8, sonuca ait bilgiler ise Tablo 2' de verilmiştir. 


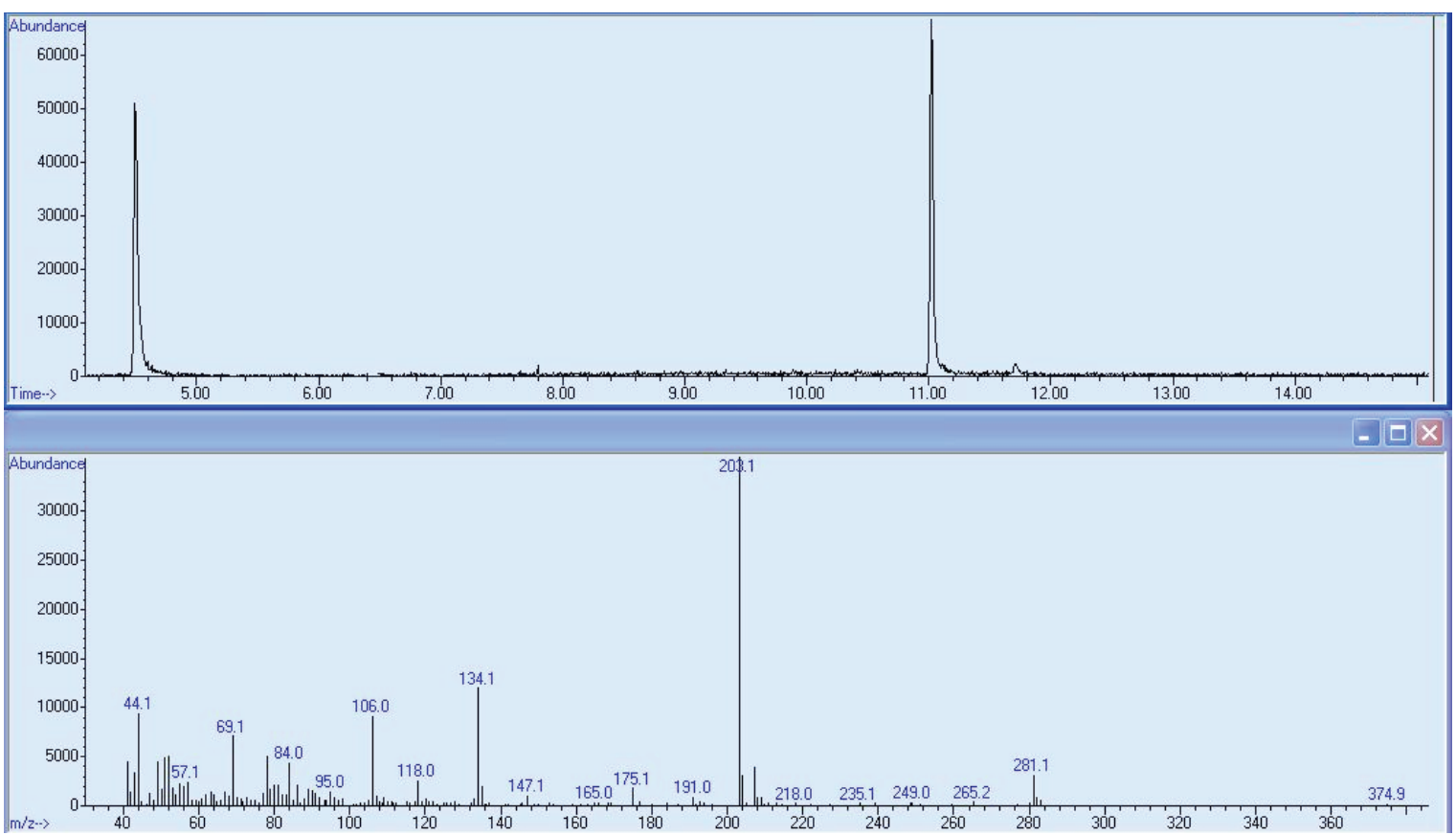

Şekil 7. Balda Gözlenen Bozunma Ürününe Ait Kromatogram ve Spektrum.

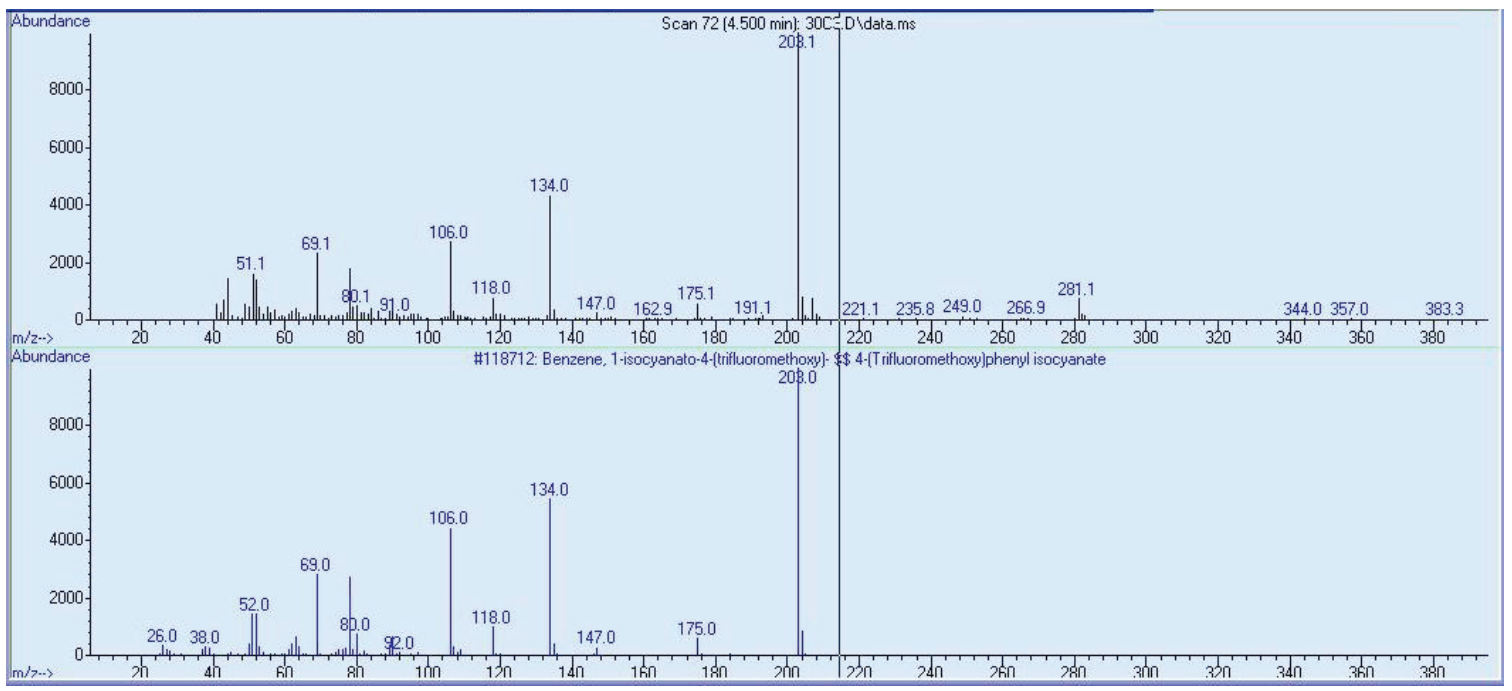

Şekil 8. Cihaza Ait Kütüphane Karşılaştırma Sonucunu Gösteren Spektrum.

Tablo 2. Cihazın Yazılımında Bulunan Pestisit, NIST ve Wiley Kütüphaneleri Tarama Sonucu.

\begin{tabular}{ll}
\hline Ad1 & $:$ 4- (triflorometoksi)fenil izosiyanat \\
CAS Numarası & $: 035037-73-1$ \\
Entry Number & $: 118712$ \\
Molekül Formülü & $: \mathrm{C}_{8} \mathrm{H}_{4} \mathrm{~F}_{3} \mathrm{NO}_{2}$ \\
Diğer Bilgiler & \\
QI=899 & Kaynak=NS-3-5588-0 \\
Eşleşme Kalitesi & $: 93$ \\
Molekül Ağırlığ 1 & $: 203,02$ \\
\hline
\end{tabular}

\subsection{Sonuç ve Değerlendirme}

Yaptığımız çalışmalar ışı̆̆ında görülmüştür ki; geliştirilen yöntem balda indoksakarb analizini mümkün kılan kolay, basit ve hızlı bir yöntem olup literatürde ilk defa çalışılmıştır. John-Wiley ve Elsevier anahtar sözcük taramalarında ve ayrica Chemical Index'lerde yapılan taramalarda, balda indoksakarb analizi ile ilgili bir çalışmaya rastlanılmamıştır. Bizim çalışmamızda öncelikle sıvı-sıvı ekstraksiyon yöntemi için çözücü seçimi yapılmıştır. Bunun için kloroform, 
etil asetat:kloroform $(80: 20(\mathrm{~h} / \mathrm{h})$, asetonitril ve diklorometan organik çözücüleri denenmiş olup en iyi geri kazanım yüzdesini, $\% 95$ güven aralığında $(\mathrm{n}=6), \% 78,7 \pm 5,5$ ile diklorometan vermiştir. 1 gram bal örneği kullanıldığında tespit ve tayin sinırları sirasıyla $0,03 \mathrm{mg} / \mathrm{kg}$ ve $0,11 \mathrm{mg} / \mathrm{kg}$ olarak hesaplanmıştır. Bu tespit sınırı aynı zamanda Avrupa Birliği Komisyonu tarafindan belirlenen maksimum kalıntı limitleri mevzuatına göre ballarda izin verilen indoksakarb kalıntı limiti olan $0,05 \mathrm{mg} / \mathrm{kg}$ değerini de sağlamakta olup ilgili mevzuata uygun bir şekilde analiz yapılmasına da imkan sağlamaktadır [16]. Geliştirilen metot kolay uygulanabilir, hızlı ve balda indoksakarb kalıntısının belirlenmesi için uygulanabilir bir yöntemdir. Yöntemin uygulanması sırasında 1 gram bal örneğinden indoksakarbın ekstraksiyonu için 2 defa 2'şer $\mathrm{mL}$ diklorometan kullanılmalı ve her defasında ayrılan organik fazlar birleştirildikten sonra buharlaştırılarak GC- MS analizi için hazır hale getirilmelidir.

Oda sıcakllğ̆, $30^{\circ} \mathrm{C}$ ve $40^{\circ} \mathrm{C}^{\prime}$ de bekletilmiş olan market balı, kestane, çam ve çiçek balı örnekleri indoksakarb ile kirletildikten sonra belirli aralıkla ekstraksiyon işlemi yapılmıştır. İndoksakarb miktarlarındaki değişim sonuçları incelendiğinde; çiçek balı örnekleri için oda sicaklı̆̆ı, $30^{\circ} \mathrm{C}$ ve $40{ }^{\circ} \mathrm{C}$ ' de sırasıyla $\% 61,00 ; \% 57,60$ ve $\% 61,22$ azaldığı görülmüştür. Benzer azalma miktarları kestane balı örneklerinde de tespit edilmiş olup değerler oda sıcaklığ, $30^{\circ} \mathrm{C}$ ve $40^{\circ} \mathrm{C}^{\prime}$ de sırastyla $\% 62,23 ; \% 64,54 ; \% 57,50$ 'dir. Çam balı örneklerinde oda sicaklığ $1,30^{\circ} \mathrm{C}$ ve $40^{\circ} \mathrm{C}^{\prime}$ de sirasiyla 60,$19 ; \% 64,06 ; \% 67,29$; ayçiçeği balı örneklerinde ise oda sıcaklığı, $30^{\circ} \mathrm{C}$ ve $40^{\circ} \mathrm{C}$ ' de surasiyla $\% 61,45$; $\% 66,92$; $\% 64,57^{\prime}$ lik bir azalma tespit edilmiştir. 8 ay süresince yapılan analizler sonucunda indoksakarb miktarlarında meydana gelen azalma miktarları oldukça anlamlı olup pH'sı 4,0-4,50 arasında olan bal örnekleri için beklenen bir sonuçtur. Çalışmamızın en önemli bulgularından biri de indoksakarbın bal ortamında 4-(triflorometoksi)fenil izosiyanat bozunma ürününü vermesi olmuştur. İndoksakarbın bal ortamındaki bu bozunma ürününe literatürde ilk defa rastlanılmıştır. Sağlık açısından bu bozunma ürününün ileri reaksiyonlar vermeden kalabilmesine balda fazla miktarda bulunan polihidroksi bileşiklerinin neden olduğu düşünülmektedir [19].

Dünyadaki endüstriyelleşmenin hızlı yayılımı, yeni teknolojilerin doğuşu, şehirlerin ve köylerin etrafındaki artan nüfus sebebiyle devamlı çarpık bir şekilde genişleyen kentleşme ve buna bağlı ihtiyaçların karşılanmasını sağlamak için yapılan teşebbüslerin hepsi ile pestisitlerin de aralarında olduğu kimyasal maddelerin aşırı miktarlarının tüketimi birbiriyle yakından ilişkilidir. Yaptığımız çalışma arılara olan zehirliliğinin yüksek olduğu bilinen indoksakarb adlı pestisitin ve tespit edilen bozunma ürünün bal ve bal ürünlerine geçmesi sonucu bu ürünleri kullanan insanlardaki etkisinin değerlendirilmesi bakımından önemli bir katkı sağlayacaktır.

\section{KAYNAKLAR}

[1] Tankiewicz, M., Fenik, J., ve Biziuk, M. (2010). Determination of organophosphorus and organonitrogen pesticides in water samples. Trends Analyt. Chem., 29(9), 1050-1063.

[2] Sarver, J.W. (1996). Acute oral toxicity study with DPX-MP062 technical (approximately 75\% DPX- KN128 and $25 \%$ DPX-KN127) in male and female rats. Unpublished report No. HLR 910-96 from DuPont Haskell Laboratory, Newark, Delaware, USA. Submitted to WHO by E.I. du Pont de Nemours and Company, Wilmington, Delaware, USA.

[3] Shashibhushan, J., Huggi, V., Sunil Kumar, N., Poojari, M., Bobba, R. (2015). Indoxacarb Poisoning Presenting as Methemoglobinemia and Seizure. J. Assoc. Physicians India., 63(12), 85-86.

[4] Souza Tette, P.A., Rocha Guidi, L., de Abreu Glória, M.B., Fernandes, C. (2016). Pesticides in honey: A review on chromatographic analytical methods. Talanta, 149, 124-141.

[5] Heinzen, H., Nollet, L.M.L., Fernandez-Alba, A.R. (2017). Multiresidue Methods for the Analysis of Pesticide Residues in Food, 1.bask1, CRC Press, Taylor-Francis Group, Boca Raton, Florida, U.S..

[6] Kumar Das, S. (2014). Recent Developments in Clean up Techniques of Pesticide Residue Analysis for Toxicology Study: A Critical Review. Univers. J. Agric. Res., 2(6), 199-203.

[7] Merkle, S., Kleeberg, K.K., Fritsche, J. (2015). Recent Developments and Applications of Solid Phase Microextraction (SPME) in Food and Environmental Analysis-A Review. Chromatography, 2, 293-381.

[8] Formica, G. (1984). Gas chromatographic determination of residues of bromopropylate and two of its degradation products in honey. J. Assoc. Off. Anal. Chem., 67(5), 896.

[9] Blasco, C., Fernandez, M.,Pico, Y., Font, G. (2004). Comparison of solid-phase microextraction and stir bar sorptive extraction for determining six organophosphorus insecticides in honey by liquid chromatography-mass spectrometry. J. Choromatogr. A, 1030(1-2), 77-85.

[10] Rissato, S. R., Galhiane, M.S., Knoll, F.R.N., Apon, B.M. (2004). Supercritical fluid extraction for pesticide multiresidue analysis in honey: determination by gas chromatography with electron-capture and mass spectrometry detection. J. Choromatogr. A, 1048(2),153-159.

[11] Jimenéz, J. J., Bernal, J.L., del Nozal, J., Martin, T., Mayorga, A.L. (1998). Solid-phase microextraction applied to the analysis of pesticide residues in honey using gas chromatography with electron-capture detection. J. Choromatogr. A, 829(1-2), 269-277.

[12] Korta, E., Bakkali, A., Berrueta, L.A., Gallo, B., Vicente, F. (1999). Kinetics and mechanism of amitraz hydrolysis in aqueous media by HPLC and GC-MS. Talanta, 48, 189-199.

[13] Jimenéz, J. J., Bernal, J.L., del Nozal, J., Toribio, K., Martin, T. (1998). Gas chromatography with electron-capture and 
nitrogen-phosphorus detection in the analysis of pesticides in honey after elution from a Florisil column: Influence of the honey matrix on the quantitative results. J. Choromatogr. A, 823 (1-2), 381-387.

[14] Bernal, J.L., Jimenez, J.J., del Nozal, J., Higes, M., Llorente, J. (2000). Gas chromatographic determination of acrinathrine and 3-phenoxybenzaldehyde residues in honey. J. Choromatogr. A, 882(1-2), 239-243.

[15] Korta, E., Bakkali, A., Berrueta, L.A., Gallo, B., Vicente, F., Kilchenmann, V., Bogdanov, S. (2001). Study of acaricide stability in honey. Characterization of amitraz degradation products in honey and beeswax. J. Agric. Food Chem., 49(12), 5835-5842.

[16] Korta, E., Bakkali, A., Berrueta, L.A., Gallo, B., Vicente, F. (2001). Study of semi-automated solid-phase extraction for the determination of acaricide residues in honey by liquid chromatography. J. Choromatogr. A, 930(1-2), 21-29.

[17] Jimenez, J.J., Bernal, J.L., del Nozal, J., Novo, M., Higes, M., Llorente, J. (2000). Determination of rotenone residues in raw honey by solid-phase extraction and high-performance liquid chromatography. J. Choromatogr. A, 871, 67-73.

[18] Commission Regulation (EU) No 51/2014 of 20 January 2014 amending Annex II to Regulation (EC) No 396/2005 of the European Parliament and of the Council as regards maximum residue levels for dimethomorph, indoxacarb and pyraclostrobin in or on certain products is to be incorporated into the EEA Agreement.

[19] Çubuk, S. (2008). Bal Örneklerinde Indoxacarb Kalıntısının ve Bozunma Ürünlerinin Tayini İçin Yöntem Geliştirilmesi. Doktora Tezi, Tez Danışmanı: Prof. Dr. Adnan Aydın. Marmara Üniversitesi, Türkiye. 